\title{
Investigation of Radio Frequency Interference (RFI) Profile and Determination of Potential Astronomical Radio Sources
}

\author{
Z. S. Hamidi ${ }^{1, *}$, N. N. M. Shariff ${ }^{2, * *}$ \\ ${ }^{1}$ MARA University of Technology, 40450, Shah Alam, Selangor, Malaysia \\ ${ }^{2}$ Department of Science and Technology Studies, University of Malaya, 50603, \\ Kuala Lumpur, Malaysia \\ *,**E-mail address: zetysh@salam.uitm.edu.my,nur.nafhatun@um.edu.my
}

\begin{abstract}
In this article, we have recognized a Radio Frequency Interference (RFI) sources that can potentially affect for radio astronomical observation. The main objective of this surveying is to test and qualify the potential of radio astronomical sources that can be observed in Malaysia generally. Analysis process focuses on the high sources that contribute the pollution and the significant region that can be considered for astronomical purpose beginning 1-2000 MHz. It was found that 13 individual sources contribute as a noise and mostly are telecommunication and radio navigation applications. We then compared of the RFI profiles based on three different periods in order to observe the variety of the signals. The main regions that still excellent to do an observation are: $13.36-13.41$ $\mathrm{MHz}$ (solar), (25.55-25.67) MHz (Jupiter) and (37.50-38.25) MHz (Continuum) respectively. This work is also an initiative of the International Space Weather Initiative (ISWI) project where Malaysia is one of the countries that involve in e-CALLISTO (Compound Astronomical Low Cost Low Frequency Transportable Observatory) network project. Some suggestions are recommended in order to improve the quality of the radio frequency profile.
\end{abstract}

Keywords: Radio Frequency Interference (RFI); radio astronomy; RFI sources

\section{INTRODUCTION}

Determination of Radio Frequency Interference (RFI) is very important progress in order to discover the potential radio astronomical sources. This study is currently one of a main sub-research in radio astronomy in Malaysia [1]. Continuity RFI surveying has been conducted at several sites such as at the University of Malaya [2], Langkawi, National Space Centre Banting [3], and other relevant sites to choose the best candidate site for radio astronomical research. Previous study also focused on the effect of population density on the RFI profile [4]. The radio wavelength just not only covers a wide range with the longest wavelength compare other types of electromagnetic windows, but is also contain a very good potential to determine a new celestial object in our Universe. However, the main challenges of the next generation radio telescope for astronomy are its capacity to cope with increasing polluted of RFI [5]. Due to the developments in electronics technology, the need for electromagnetic shielding has increased [2]. In recent years, due to the increasing conflict 
between scientific and commercial users of the radio spectrum Radio frequency Interference (RFI) is a serious problem for passive and active radio and microwave sensing of the Earth. As a result, it is very significant to verify the unwanted signals which are emitted due to the massive global increase. In order to determine a strategic site for radio astronomical research an effort has been made by penetrating a site that has very minimum radio frequency interference. An RFI is often localized in time and frequency, relative to the integration times and pre-detection bandwidths over which a space borne microwave radiometer acquires its samples of the brightness temperature. Based on this issue, we analyze the Radio frequency Interference (RFI) profile at three (3) different periods. This preliminary work also is a part of an initiative of the International Space Weather Initiative Program (ISWI) [6]. In this committee, we are hosting the e-CALLISTO (Compound Astronomical Low Cost Low Frequency Transportable Observatory) network [7]. In previous work, we have compared the RFI level at two (2) different sites [8]. Therefore, in this work, we need to identify all RFIs sources in the range of $1 \mathrm{MHz}$ till $2000 \mathrm{MHz}$ continuously. This study is to intend the best range of wavelength that possible for radio observation purpose.

\section{MEASUREMENT SETUP AND OBSERVATIONS}

We monitored an RFI profile at frequencies from 1-2000 MHz located at Faculty of Applied Sciences, Universiti Teknologi MARA $\left(3^{\circ} 5^{\prime} 00^{\prime \prime} \mathrm{N} 101^{\circ} 32^{\prime} 00^{\prime \prime} \mathrm{E} / 3.0833333^{\circ} \mathrm{N}\right.$ $101.5333333^{\circ} \mathrm{E}$ ). A combination of detachable 9' ' whip antenna with gain $30 \mathrm{~dB}$ and $0.37 \mathrm{~dB}$ of NF connected with Radio Frequency Field Strength Analyzer Figure 1).

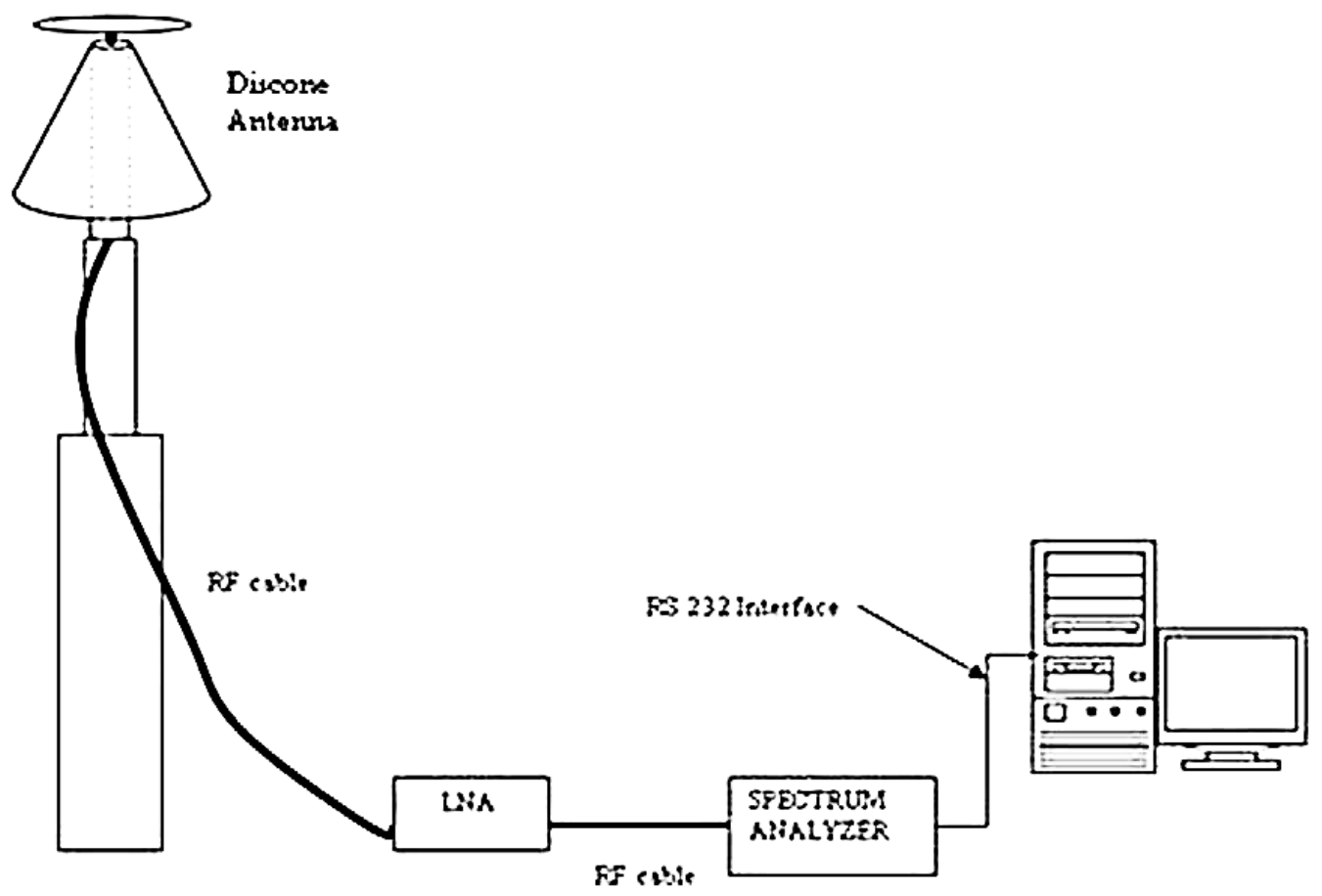

Figure 1. RFI system connection.

The measurement system is routinely gaining calibrated by using the low noise amplifier. This observation has been done from 9.00 am till 17:00 pm. In order to avoid the unnecessary noise due to weather condition, the strength of RFI were measured only when the atmosphere was optically clear so that the path of light through the Earth's atmosphere is 
completely stable. We also identified the peak signals of the frequency from the spectrum analyzer. Data acquisition hardware consists the strength of noise level in $\mathrm{dB}$ unit which will be transferred to a computer for further analysis. We can also predict the sources that caused the interference. The minimum RFI from the wavelength will give the best range for astronomical purpose while the maximum level of RFI, in contrast, is good to identify the elements that make it polluted. All digital electronics are located in a single screened enclosure to minimize self-generated RFI.

\section{RESULTS AND ANALYSIS}

It was found that 13 individual sources contribute as a noise and mostly are telecommunication and radio navigation applications. The RFI noise levels were initiated to be widespread in RFI at $800 \mathrm{MHz}-1200 \mathrm{MHz}$ region comes from a mobile phone application (Maxis, Celcom and Digi) while moderate RFI at $1600 \mathrm{MHz}-2000 \mathrm{MHz}$ due to earth exploration and radio navigation satellite.

Table 1. The five windows of RFI survey.

\begin{tabular}{|c|c|c|}
\hline Frequency range $(\mathrm{MHz})$ & Sources of RFI & $\begin{array}{l}\text { Specific Frequency } \\
(\mathrm{MHz})\end{array}$ \\
\hline $1-400$ & $\begin{array}{ll}\text { 1. } & \text { UFM-Radio } \\
\text { 2. } & \text { Hot FM Signal }\end{array}$ & $\begin{array}{l}93.6 \\
97.6\end{array}$ \\
\hline $400-800$ & 1. Broadcasting & $800-922.5$ \\
\hline $800-1200$ & $\begin{array}{ll}\text { 1. } & \text { Mobile (GSM) } \\
\text { 2. } & \text { DIGI } \\
\text { 3. } & \text { Celcom } \\
\text { 4. } & \text { Maxis }\end{array}$ & $\begin{array}{l}922.5-960 \\
931-933 \\
933-935 \\
950-960\end{array}$ \\
\hline $1200-1600$ & $\begin{array}{l}\text { 1. Earth exploration and } \\
\text { radio navigation satellite } \\
\text { 2. mobile satellite }\end{array}$ & $\begin{array}{l}1215-1222.5 \\
1507.5-1525\end{array}$ \\
\hline $1600-2000$ & $\begin{array}{ll}\text { 1. } & \text { Mobile (GSM) } \\
\text { 2. } & \text { DIGI } \\
\text { 3. } & \text { Celcom } \\
\text { 4. } & \text { Maxis }\end{array}$ & $\begin{array}{c}1800-1877.5 \\
1800-1812.5 \\
1825-1835 \\
1852-1875\end{array}$ \\
\hline
\end{tabular}

An analysis of RFI spectrum profiles of each time: (i) 9:00 am, (ii) 14:00 pm and (iii) 17:00 pm are presented in Figure 2, 3 and 4 respectively. 
Noise Level $(\mathrm{dBm})$ versus Frequency $(\mathrm{MHz})$

Frequency (MHz)

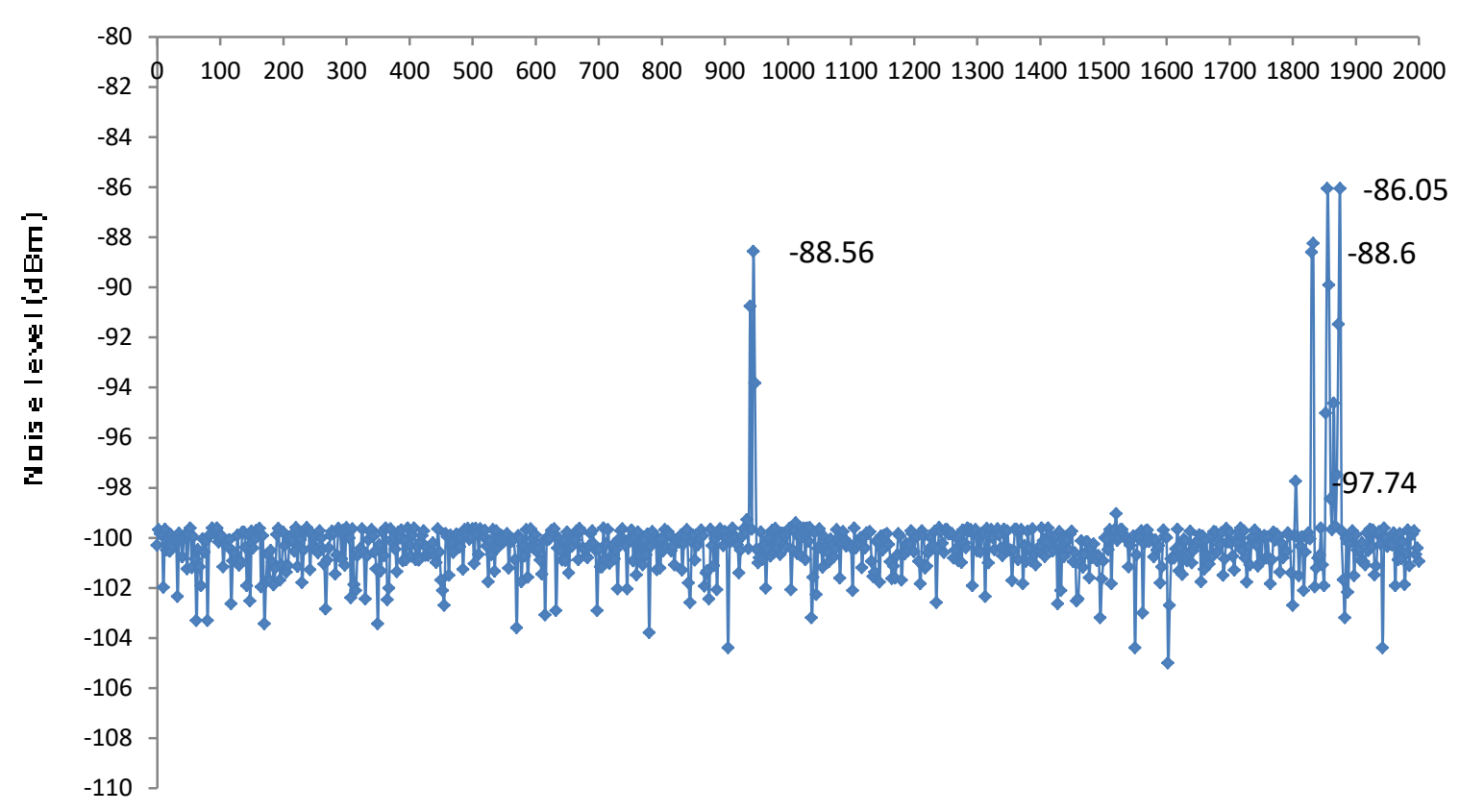

Figure 2. RFI spectrum profile at Faculty of Applied Sciences at 9:00a.m.

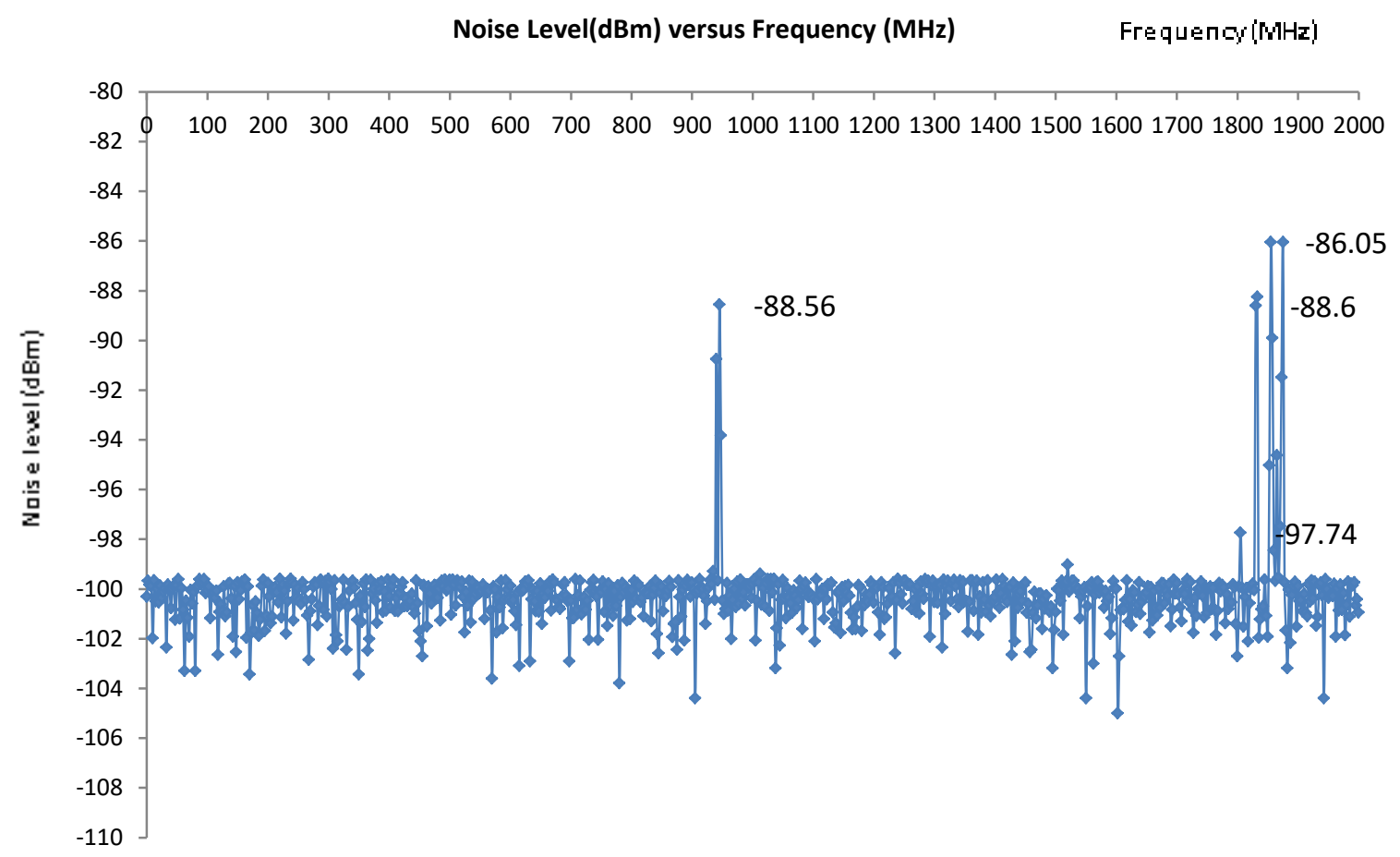

Figure 3. RFI spectrum profile at Faculty of Applied Sciences at 14:00 p.m. 


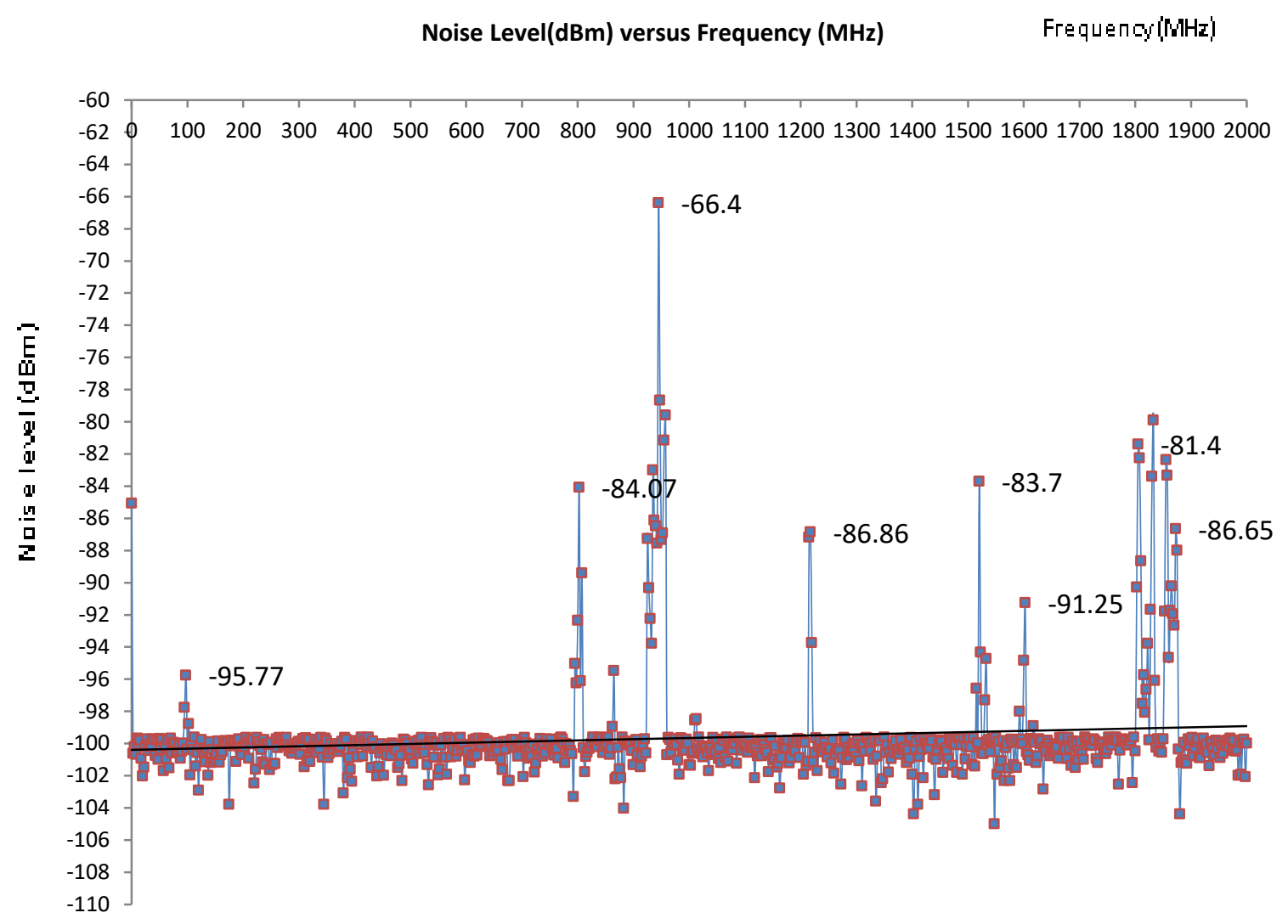

Figure 4. RFI spectrum profile at Faculty of Applied Sciences at 17:00 p.m.

According to the results, Faculty of Applied Sciences has the value of noise level with an average of $-100.007 \mathrm{dBm}$. It means that this site is a moderated site for radio observations. It was found that there is no difference of RFI profile at 9:00 am and 14:00 pm. We can say that the signal of the sources remains consistent within 5 hours. However, during 17:00 pm, the profile changed obviously. There are a few signals that can be found in the range of 1100 $\mathrm{MHz}-1600 \mathrm{MHz}$. The peak of signals is also becoming increasing up to $-66.4 \mathrm{dBm}$.

It should be noted that The Malaysian Communication Multimedia Commission had protected the eight (8) exclusive frequency bands for radio astronomical observations. Based on our analysis, there are three main regions are still at a very minimum of RFI level which are: 13.36-13.41 MHz (solar), (25.55-25.67) $\mathrm{MHz}$ (Jupiter) and (37.50-38.25) $\mathrm{MHz}$ (Continuum) observations respectively. There are also a signal from other services, as well as from our own poorly-engineered equipment, sometimes contaminate our bands. Therefore, a continuous observation of RFI is important.

Unfortunately, in the band $800-1200 \mathrm{MHz}$ and $1600-2000 \mathrm{MHz}$, there are more than 4 individual sources of RFI with a signal of more than $\sim 90 \mathrm{dBm}$. This range can be considered as the most polluted range compares the others. Therefore, every practicable effort should be made to avoid the assignment of frequencies to stations in the fixed and mobile services that could interfere with radio astronomy. A quantity of mitigation can be achieved by frequent data dumps and the excision of RFI, or by real-time detection and blanking of the receiver, or by more sophisticated algorithms. 
Table 2. Potential astronomical sources at Faculty of Applied Sciences.

\begin{tabular}{cccc}
\hline Specific Frequency range $(\mathrm{MHz})$ & Average strength $(\mathrm{dBm})$ & RFI level & Suitable observation \\
\hline $13.36-13.41$ & -103 & Very low & Solar \\
\hline $25.55-25.67$ & -101 & Very low & Jupiter \\
\hline $37.50-38.25$ & -102.5 & Very low & Continuum observation \\
\hline $73.00-74.60$ & -95 & low & Pulsar \\
\hline $322.00-328.65$ & -91 & medium & Deutrium observation \\
\hline $406.00-410.00$ & -96 & low & Pulsar \\
\hline $1400.00-1427.00$ & -103 & Very low & Hydrogen-line \\
\hline
\end{tabular}

It could not be denied that the radio spectrum is a finite resource, on which humanity makes many demands. Hence, we need a regulatory protection at the highest level, strong local protection, and self-protection through interference mitigation techniques. Continuances surveying should be done from time to time in order to detect new sources of interference and monitoring the level of RFI. Thus, RFI detection and mitigation strategies are needed to ensure a radiometer will not be damaged by extreme RFI (survivability). The International Telecommunication Union provides regulatory protection from licensed radio transmitters, through the allocation of passive frequency bands, through limits to unwanted emissions.

\section{CONCLUSION}

Overall, the RFI strengths of the Faculty of Applied Sciences, MARA University of Technology, Shah Alam showed the moderate rate although the population density in Shah Alam is very high. We can conclude that this area is the intermediate site for developing the radio astronomy research. We should highlight the importance of protecting the radio window for astronomy purpose through the campaign and the media so that they will alert and realize the consequences if no action are taken.

\section{Acknowledgement}

This work was partially supported by the PPP UM PV071/2011B grants. Special thanks to C. Monstein from ETH Zurich, Switzerland who set up and gives us training on analyzing the data. Also to National Space Agency and National Space Centre for giving us a site to set up this project and support this project. Solar burst monitoring is a project of cooperation between the Institute of Astronomy, ETH Zurich, and FHNW Windisch, Switzerland, MARA University of Technology and University of Malaya. This paper also used NOAA Space Weather Prediction Centre (SWPC) for the sunspot, radio flux and solar flare data for comparison purpose. The research has made use of the National Space Centre Facility and a part of an initiative of the International Space Weather Initiative (ISWI) program. 


\section{Biography}

Zety Sharizat Hamidi is currently a $\mathrm{PhD}$ candidate and study in Solar Astrophysics specifically in radio astrophysics at the University of Malaya. Involve a project under the International Space Weather Initiative (ISWI) and also a lecturer in School of Physics and Material Science, at MARA University of Technology, Shah Alam Selangor.

N.N.M..Shariff Her current research is communicating sustainability. She is looking forward for cross-field research i.e. solar astrophysics, light pollution measurement (mapping) and application of technology on sustainability.

\section{References}

[1] Z. Z. Abidin, Radio Astronomy Research in Malaysia: Past, Present and Future., Proc. of Space Science and Communication, 2009, pp. 179-181.

[2] Zamri Zainal Abidin, Zainol Abidin Ibrahim, Syed Bahari Ramadzan Syed Adnan, Norwati Khairul Anuar, New Astronomy 14 (2009) 579-583.

[3] Z. S.Hamidi, N. N. M.Shariff, R. Umar, Malaysia Thailand Journal of Physics 3 (2012) 6.

[4] Roslan Umar, Zamri Zainal Abidin, Zainol Abidin Ibrahim, Mohd Saiful Rizal Hassan, Zulfazli Rosli, Z. S.Hamidi, Population density effect on radio frequencies interference (RFI) in radio astronomy, ICPAP 2012, AIP Conference Proceedings, Bandung Indonesia, 2012, pp. 4.

[5] Z. Hamidi, Z. Abidin, Z. Ibrahim, N. Shariff, Indication of radio frequency interference (RFI) sources for solar burst monitoring in Malaysia, AIP Conference Proceedings 1454 (2012) 43.

[6] Z. Hamidi, N. Shariff, Z. Abidin, Z. Ibrahim, C. Monstein, Middle-East Journal of Scientific Research 12(6) (2012) 893-898.

[7] Z. Hamidi, Z. Ibrahim, Z. Abidin, M. Maulud, N. Radzin, N. Hamzan, N. Anim, N. Shariff, International Journal of Applied Physics and Mathematics 2(3) (2012) 140-142.

[8] Z. Hamidi, Z. Abidin, Z. Ibrahim, N. Shariff, U. F .S. U. Ibrahim, R. Umar, Preliminary analysis of investigation Radio Frequency Interference (RFI) profile analysis at Universiti Teknologi MARA, IEEE, 2011, pp. 311-313. 